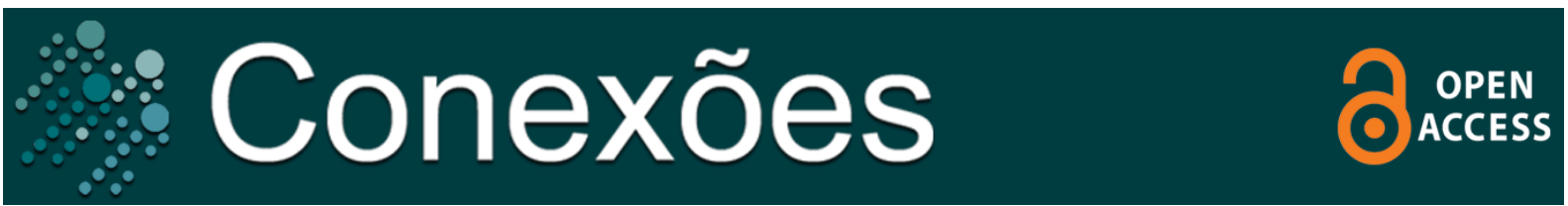

Artigo Original

\title{
Parkour, transpondo o obstáculo da competição
}

\author{
Parkour, overcoming the hurdle of competition \\ Parkour, transpondiendo el obstáculo de la competición \\ Dimitri Wuo Pereira ${ }^{1}$ \\ Rafael Batista Mattos ${ }^{2}$
}

\begin{abstract}
RESUMO
Objetivo: O parkour é uma nova versão esportiva, criado nos subúrbios de França que se opõe ao agonismo próprio da modernidade e parece confrontar as certezas que o positivismo engendra. Este trabalho tem por objetivo conhecer os praticantes de parkour e entender como concebem o conceito de competição que começa a ser disseminado nele. Método: Uma pesquisa exploratória com oitenta e quatro sujeitos foi aplicada em praticantes de todo o Brasil. Resultados: Os resultados permitem dizer que os jovens são aqueles que mais procuram o parkour e que os grupos são heterogêneos, ainda se percebe que as mulheres precisam conquistar seu espaço, pois não são protagonistas na modalidade. Conclusão: Verificou-se que há interesses da Federação Internacional de Ginástica em agrupar o parkour como uma de suas disciplinas e que os praticantes brasileiros não têm um consenso sobre se aceitam a competição ou não.
\end{abstract}

Palavras-chave: Parkour. Competição. Esporte.

${ }^{1}$ Serviço Nacional de Aprendizagem Comercial - SENAC, Jundiaí - SP, Brasil.

2 Universidade Nove de Julho, São Paulo - SP, Brasil.

\section{Correspondência:}

Dimitri Wuo Pereira. Rua Ernestina de Castro Marcondes, 263, casa 145, Parque da Represa, Jundiaí-SP, CEP 13214-554. Email: dimitriwuo141@gmail.com 


\begin{abstract}
Objective: Parkour is a new sport version, created in the suburbs of France that opposes to the agonism proper to modernity and seems to confront the certainties that the positivism engenders. This paper aims to know the parkour practitioners and understand how they conceive the concept of competition that begins to spread in it. Method: An exploratory survey with eighty-four subjects was applied to practitioners from all over Brazil. Results: The results allow us to say that young people are those who seek parkour the most and the groups are heterogeneous, it is still clear that women need to conquer their space, as they are not protagonists in the sport. Conclusion: It was found that there are interests of the International Gymnastics Federation in grouping parkour as one of its disciplines and that Brazilian practitioners do not have a consensus about to accept or not the competition.
\end{abstract}

Keywords: Parkour. Competition. Sport.

\title{
RESUMEN
}

Objetivo: Parkour es una nueva versión deportiva, creada em los suburbios de Francia que se opone al agonismo de la modernidad y enfrenta las certezas que engendra el positivismo. Este trabajo tiene como objetivo conocer a los profesionales del parkour y comprender cómo conciben el concepto de competición que está comenzando a difundirse en él. Método: Se aplicó una investigación exploratoria con ochenta y cuatro sujetos practicantes del parkour de todo Brasil. Resultados: Los resultados nos permiten decir que los jóvenes son los que más buscan el parkour y que los grupos son heterogéneos, todavía está claro que las mujeres necesitan conquistar su espacio, ya que no son protagonistas en el deporte. Conclusión: Se descubrió que hay intereses de la Federación Internacional de Gimnasia en agrupar el parkour como una de sus disciplinas y que los practicantes brasileños no tienen un consenso sobre si aceptar la competición o no.

Palabras Clave: Parkour. Competición. Deporte. 


\section{INTRODUÇÃO}

O parkour já deixou de ser uma novidade entre as práticas corporais, apesar de seu surgimento recente, por volta da última década do século XX, ele é muito visto na mídia em filmes, propagandas, revistas e na internet, além disso, sua prática difundiu-se pelo mundo com extrema velocidade, sendo praticado principalmente por jovens.

A ideia do parkour surgiu na década de 1980, nos subúrbios de Lisses na França, com um grupo de jovens liderados por David Belle, que sob influência do parcours du combattant, treinamento militar praticado por seu pai Raymond e do Método Natural Ginástico, de Georges Hebert, que preconizava o desenvolvimento físico e moral do indivíduo através de exercícios de locomoção em ambientes naturais (STRAMANDINOLLI; REMONTE; MARCHETTI, 2012). Ele e seus amigos desenvolveram treinamentos corporais com objetivo de ultrapassar obstáculos da paisagem urbana do subúrbio onde viviam, buscando sempre a eficiência no enfrentamento dos riscos que seus movimentos exigiam ao ultrapassar os obstáculos da cidade. Como estas formas de treinamento corporal valorizavam o altruísmo, a solidariedade e a superação pessoal, o parkour incorporou esses ensinamentos em sua filosofia e "Ser forte por ser útil" e "Ser e durar" passaram a ser lemas dos praticantes, que diferente das práticas esportivas usuais não estavam preocupados em vencer o outro, mas fortalecerse para ajudar o outro.

Por outro lado, o esporte moderno se configurou a partir da revolução industrial como um processo de dominação do ser humano sobre a natureza e fundamentado na produtividade, carregando a característica agonística (CALLOIS, 1990), como sua principal marca, desde os Jogos Olímpicos da Grécia Antiga, ou seja, para a maioria das pessoas pensar o esporte sem competição é destituir da prática corporal seu caráter esportivo. Assim, o parkour que por sua recente aparição no cenário da cultura de movimento pretende se desvincular do conceito competitivo, não se ajusta a categoria do esporte competitivo, pelo menos em tese.

Alguns estudos identificam o parkour como "Arte do deslocamento", em outras palavras, uma atividade na qual o indivíduo se entrega com o objetivo de sair de um ponto $A$ para um ponto $B$ buscando a fluidez do seu próprio corpo em movimento, mantendo distância do conceito de competição entre duas ou mais pessoas.

Para os traceurs, a despeito de a atividade assemelhar-se à prática desportiva e de favorecer o condicionamento físico, parkour não é esporte. Não há um ponto de chegada, não é possível apontar melhores ou piores traceurs, e a competição é rejeitada com veemência. Também não existem locais fixos para treinos, pois a atividade acontece onde quer que o praticante exercite sua aptidão 
em superar os obstáculos que surgirem no trajeto escolhido (SILVA; COSTA; CARVALHO, 2011, p. 135).

Carvalho e Pereira (2008) a esse respeito se perguntam até quando será possível manter o parkour como uma prática corporal ausente das disputas, pois, a competição carrega valores enaltecidos na sociedade, como: A exibição, o dinheiro, o pódio, a superioridade, o orgulho, a vitória, a vantagem, o poder. Elementos aos quais a juventude se sente atraída, pois conferem ascensão social e pessoal que destacam o indivíduo da multidão, proporcionando-lhe o status de herói.

Mesmo tendo surgido como não competitivo (FERNANDES; GALVÃO, 2016), com o decorrer do tempo, a pressão para que ele se conforme aos ditames do esporte moderno e consequentemente se torne uma atividade competitiva aumentou, a possibilidade de ser incluído ao programa olímpico selaria essa nova visão sobre o parkour, o que reconfiguraria sua estrutura inicial e o tornaria indistinto de outras modalidades.

Dessa forma, surgem algumas perguntas neste estudo. Quais as características dos praticantes de parkour no Brasil? Acredita-se que identificando essas pessoas será possível fazer inferências a respeito de como a cultura do parkour está presente em suas vidas. Outra questão fundamental que este estudo espera responder é: Como os praticantes enxergam a presença da competição no parkour?

O objetivo deste estudo é revelar como se constitui na prática do parkour a relação com a competição esportiva, visto que, a cultura do parkour surgiu em contraposição ao esporte competitivo (ALVES; CORSINO, 2013) e dia a dia é confrontada com o conceito de esporte, no qual para ser esportiva e gozar das prerrogativas de ser um esporte, com apelo midiático, patrocinadores, dinheiro, aumento do número de praticantes, mais dos espaços de prática, reconhecimento social, ele precisa ter vitoriosos e perdedores. Isto é, o conceito agonístico prevalecendo sobre a ludicidade e a cooperação.

\section{MÉTODO}

Esta pesquisa se caracteriza como exploratória descritiva porque busca delimitar o campo de estudo, mapeando as condições de manifestação do objeto, ao mesmo tempo em que tenta analisar e identificar as causas das ocorrências dos fenômenos, usando abordagem quantitativa e qualitativa (SEVERINO, 2007).

Utilizou-se como instrumento um questionário, construído pelos pesquisadores e aplicado através de um formulário Google com distribuição pelas redes sociais (Facebook e WhatsApp), com intuito de alcançar a maior quantidade de sujeitos possível de todo o país. O envio dos convites para 
responder o questionário foi feito em grupos de parkour na internet, que agregam grande parte dos praticantes, pois se sabe que a difusão da prática do parkour ocorreu no final do século $X X$ e início do século XXI, utilizando principalmente a internet como meio de divulgação da cultura e dos atores sociais do parkour, como aponta Fernandes (2018).

Na primeira parte do questionário foi possível reconhecer as informações referentes ao perfil dos praticantes em relação à idade, região em que mora, local onde pratica, tempo de prática, conhecimento sobre a modalidade e forma de prática. Na segunda parte, as perguntas versaram sobre a opinião dos praticantes a respeito da relação do parkour com a competição. O questionário continha perguntas fechadas e foi aplicado antes com um traceur experiente como projeto piloto, somente depois foi enviado ao público-alvo do estudo, a fim de saber se as perguntas eram pertinentes e facilmente compreendidas.

A amostra probabilística contou com 84 sujeitos, sendo 76 homens e 8 mulheres, com média de idade de 23,4 anos e desvio padrão de + ou - 5,12 anos. Os participantes assinaram o Termo de Consentimento Livre e Esclarecido no próprio formulário e tinham acesso via email e telefone com os pesquisadores para que pudessem retirar o consentimento a qualquer momento da pesquisa. Como critério de exclusão, não foram aceitas respostas de pessoas com menos de 18 anos. A pesquisa foi aprovada pelo Comitê de Ética da Universidade Nove de Julho sob parecer número 82.781 .

A análise de dados usou o programa Excell Office (7.0), fornecendo média, desvio padrão e porcentagem, sendo possível fazer uma análise comparativa com a literatura acadêmica voltada ao parkour e a outras atividades esportivas e de lazer a respeito do tema.

\section{RESULTADOS E Discussão}

\section{QUEM SÃO OS TRACEURS E AS TRACEUSES}

A delimitação do perfil dos praticantes denominados traceurs (homens) e traceuses (mulheres) nos permite identificar quem são e de onde vem essas pessoas. Verifica-se que a maioria são provenientes da região Sudeste (gráfico 1 ), sendo que entre os sujeitos desta pesquisa $52,3 \%$ são da capital paulista, infere-se que sendo uma grande metrópole a cidade de São Paulo é um palco perfeito para a disseminação do parkour, afinal, a atividade se encaixa muito com a revisitação do espaço urbano como local de desafio e ressignificação, que segundo Orlandi (2014) faz que ocorra uma metamorfose entre sujeito e espaço, no qual um transforma o outro.

Como a distribuição pela internet dos questionários, o alcance da pesquisa permitiu atingir pessoas de todas as regiões do país. Como essa é uma prática 
corporal que pouco é difundida na educação física escolar, entende-se que sua difusão pelas redes sociais, pela mídia e pela internet em geral foi responsável por levar essa cultura para todos os cantos do Brasil (SILVA, 2012), isto demonstra uma necessidade dos cursos de formação em Educação Física atentarem-se ao parkour como conteúdo na formação de professores.

Outro fato relevante é a participação de $19 \%$ de sujeitos provindos do Nordeste, alguns aspectos podem ser discutidos a esse respeito. Um primeiro é o baixo custo da prática e como a região Nordeste concentra menor distribuição de renda, então uma modalidade que não necessita de equipamentos e materiais específicos é viável para toda a população. Fernandes (2018) realizou sua pesquisa somente com praticantes da Bahia e Pernambuco mostrando que nessas regiões há grupos organizados de parkour, o que reforçam os dados aqui encontrados. Em Segundo lugar, interessa também observar que municípios como Nova Mutum (MT), Águas Lindas (GO), Santa Luzia (RO), Mucajaí (RR), Nossa Senhora do Socorro (SE), Meruoca (CE), entre outros municípios pequenos do Brasil estão representados na pesquisa, o que indica um espalhamento do parkour por todo o país, não sendo uma atividade exclusiva de grandes centros urbanos como se pode imaginar e justificando o alcance das mídias sociais na divulgação da atividade.

\section{Distribuição dos sujeitos por regiões do Brasil}

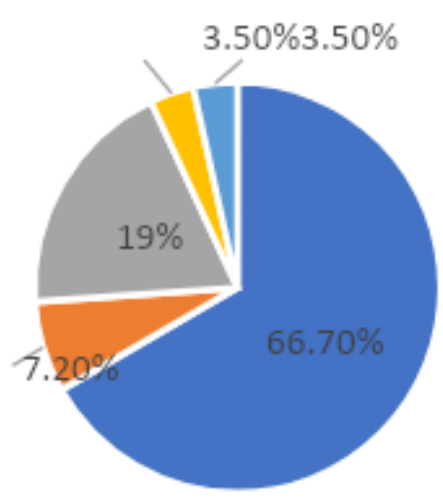

\section{SUDESTE SUL NORDESTE NORTE I CENTRO OESTE}

Gráfico 1 - distribuição dos praticantes de parkour pelo Brasil

A média de idade dos sujeitos ficou em 23,4 anos (+ ou - 5,12 anos), o que corresponde às amostras de Palavro (2016) e de Fernandes (2008) para os grupos pesquisados por esses autores. O desvio padrão apresenta uma dispersão no grupo em relação à faixa etária, mas é possível considerar que os traceurs e traceuses podem ser considerados como juventude. Leite et al. (2011) obtiveram uma amostra com faixa etária inferior, porém com menores de idade participando do estudo e nesta pesquisa estes foram excluídos, pois por questões éticas de uma pesquisa distribuída on line, decidiu-se por incluir apenas sujeitos 
declarados maiores de 18 anos. Acredita-se que essa é uma limitação deste estudo que buscou informações via web, mas a característica de jovialidade continua presente na amostra. Portanto, acredita-se que há um padrão de idade para os praticantes do parkour, quer seja por sua difusão principal ocorrer através dos meios tecnológicos, quer por exigir muito fisicamente dos praticantes, afastando pessoas com idade superior aos 30 anos a iniciar na atividade.

O tempo de prática médio foi de 6,1 anos por pessoa com desvio padrão de + ou - 3,85 anos. Aqui se verifica também uma variação grande entre os mais e os menos experientes, o que indica um grupo bastante heterogêneo. Assim, é possível afirmar que a iniciação do parkour se dá da adolescência até os 20 anos, aproximadamente e alguns fatores ajudam a entender a iniciação cedo do parkour. Um deles é a necessidade de força muscular, agilidade, resistência e o impacto nas articulações que os saltos e quedas imprimem ao praticante, exigindo vigor físico e a ausência de lesões pré-existentes para se iniciar na modalidade (CARVALHO; VIANA, 2016). Outro, é a informalidade da atividade associada com a criação de grupos de interesse ao qual os jovens se reúnem por afinidade e afirmação social, pois nesta fase da vida a semelhança com pessoas que vivem os mesmos interesses e conflitos pessoais costuma reuni-los em tribos (UVINHA, 2001).

Contudo, observa-se que a mediana encontrada foi de 7,5 anos de prática entre os sujeitos e uma moda de 3 anos, ou seja, há diversos praticantes acima da média, o que permite dizer que são pessoas com grande experiência e que, ao que tudo indica, devem continuar transmitindo a cultura do parkour para as futuras gerações, mas, ao mesmo tempo, há muitos novatos entrando na modalidade, o que deve garantir a continuidade do esporte, porque são pessoas com jovialidade e energia renovando os significados da prática. Resta saber que princípios serão transmitidos às futuras gerações, pois as pressões sociais, podem redirecionar a filosofia do parkour.

A frequência de treinos foi de 2,78 vezes por semana, com desvio padrão de + ou $-1,1$, isto é, as pessoas praticam, em geral, entre 2 ou 3 vezes por semana, mesmo não se mostrando uma homogeneidade entre os praticantes em relação a frequência de prática do exercício. Como não é uma modalidade comumente institucionalizada, com federações, competições, publicidade, clubes, e organizações formais que o conduzem, considera-se que ele é uma prática recreativa aos usuários e cujo objetivo não é atingir o alto desempenho, mas desenvolver-se e aprimorar-se sem uma sistematização obrigatória, muito comum em outras modalidades esportivas. A moda de frequência de treino ficou em 3 vezes por semana o que vai ao encontro da atividade como promotora da qualidade de vida, considerando os traceurs e traceuses como ativos fisicamente, afinal o parkour estimula o desenvolvimento porque promove a melhora das habilidades motoras e das capacidades físicas dos indivíduos (CARVALHO; 
VIANA, 2016; GROSPRÊTRE; LEPERS, 2016), mesmo que se considere que há certa inconstância na atividade, afinal a atividade é praticada em ambientes abertos, predominantemente ao ar livre, como constata a literatura (LEITE et al. 2011).

A respeito do local onde desenvolve sua atividade verificou-se que nenhum dos participantes pratica apenas em academias especializadas de parkour. O que prevalece é a prática em parques, praças e espaços públicos em geral, mais uma vez corroborando os dados encontrados por Palavro (2016). Porém, exatamente $1 / 3(33,34 \%)$ dos sujeitos utiliza academias especializadas e espaços públicos como praças e parques para desfrutar de sua atividade. A atividade do parkour ao ar livre predomina, como verificado por Silva, Costa e Carvalho (2011), todavia, existe uma parcela considerável procurando também locais privados para praticar, talvez pela facilidade de não estar sujeito às intempéries, às proibições de equipamentos públicos e privados que são usados por praticantes sem a devida autorização, pela possibilidade de manter o treinamento em dias e horários sistematizados, pelo maior controle de risco das academias e pelo fato dos obstáculos construídos criarem situações variadas para a melhora do desempenho de acordo com a necessidade da pessoa e não do ambiente em si.

Descobriu-se que 96,5\% dos respondentes afirmam conhecer a história do parkour e apenas 3 sujeitos $(3,5 \%)$ confirmando o desconhecimento das raízes da modalidade. Esse dado nos mostra que a cultura do parkour se constrói com o interesse por suas origens e sua filosofia, porque mesmo que tenha sido de modo informal, em conversas, vídeos, ou pela internet, os traceurs e traceuses se interessam em saber algo além do movimento em si. Não é incomum que praticantes de outras modalidades como voleibol, futebol, ginástica entre outras, pouco conheçam da história de suas atividades.

Outra informação obtida pela pesquisa revela que $8,3 \%$ dos sujeitos não está praticando atualmente o esporte, talvez por falta de tempo ou presença de lesão. Mas como consideraram responder o questionário, isto indica que ainda não desistiram da atividade e talvez a retomem, ou então, eles acreditam que o tempo no qual estavam praticando foi significativo para sua construção pessoal e isso pode ter algum reflexo na participação de outras pessoas. Outra pergunta do questionário ajuda a entender essa reflexão. Somente 5 pessoas $(5,9 \%)$ disseram que treinam sozinhas, ou seja, o parkour é uma prática de grupo, de tribo e a sociabilidade é fator decisivo para manter-se no esporte, portanto, aqueles que não estão praticando podem ter se afastado por não se ajustarem a um grupo e não conseguirem por qualquer motivo acompanharem um grupo de parkour.

As mulheres formam apenas $5 \%$ dos sujeitos da pesquisa, um número pequeno e que vai ao encontro dos dados de Pereira et al. (2017), em relação aos praticantes de skate, slackline e escalada. Um dos motivos que pode ser 
levantado é o fator risco e perigo comum aos esportes radicais e de aventura, que por motivos culturais tem características "masculinas" as quais as mulheres não são desafiadas desde a infância a desenvolver e que, portanto, acabam por afastar a mulher da tentativa de se aproximar do parkour. Palavro (2016) e Grosprêtre e Lepers (2016) traçando o perfil dos praticantes de parkour obtiveram, em ambos os estudos, $87 \%$ de homens e $13 \%$ de mulheres em suas pesquisas, o que demonstra a baixa participação das mulheres no parkour. Manso (2007) entrevistou o criador do parkour, David Belle, que afirma que as traceuses existem, mas que elas se escondem. Esta fala, talvez represente apenas o momento vivido pelo criador da modalidade quando foi entrevistado, mas mesmo com o avanço significativo da mulher em diversos segmentos sociais, ainda continuam como minoria em muitas modalidades esportivas, revelando um protagonismo masculino no esporte, como já discutido por Tralci e Rubio (2012, p. 271), "Algumas atletas têm claro o viés favorável que os dirigentes conferem aos homens, identificando, inclusive, o preconceito de gênero".

O perfil dos praticantes também foi observado em relação à participação feminina, ou seja, separando os dados de homens e mulheres foi possível levantar algumas hipóteses e realizar reflexões importantes. Sobre a localização destas mulheres, verificou-se que $75 \%$ delas são do Estado de São Paulo, proporção superior aos $52 \%$ de paulistas representados na média geral da pesquisa, uma indicação de que apesar do parkour estar se disseminando pelo país, isto não parece ser uma realidade quando se fala das mulheres. Talvez o preconceito em relação à prática feminina esteja ainda mais presente em regiões menos urbanizadas o que remete a reflexões sobre a dificuldade e necessidade dos próprios praticantes serem os facilitadores desse acesso da mulher ao esporte, mesmo considerando a colocação de Barros (2016), na qual explicita que no parkour há uma aceitação e união de ambos os sexos. Entende-se que a filosofia não competitiva e altruísta da qual principia a existência desta atividade deveria agregar as mulheres de forma plena, mas isso não é uma realidade, quer seja pela exigência física e risco, ou então, porque os homens continuam criando métodos e situações de aprendizagem que não contemplam a mulher e suas especificidades no ensino e incorporação de hábitos na prática.

Outra informação importante é que nenhuma mulher pratica sozinha. A prática isolada, pouco comum no parkour, pode definir um tipo de traceur autônomo e com foco em sua necessidade de desenvolvimento independente de outras pessoas e as mulheres são minoria e ainda não se apresentam como dispostas a treinar mesmo que ninguém esteja com elas. Fernandes (2018) em sua pesquisa sobre gênero no parkour identificou que as mulheres são consideradas inferiores em três categorias frente aos homens: na biológica elas têm menos força e resistência, na psicológica elas apresentam mais inseguras e cautelosas e na social o homem domina o saber ensinar e tem liberdade para agir nos espaços de prática, apontando para o parkour como uma prática de 
resistência para as mulheres frente ao gênero masculino.

Wheaton e O'Loughlin (2017) apontam que o ensino do parkour nas aulas de educação física escolar e em grupos específicos para mulheres, com professoras, pode facilitar o acesso tanto aos menos habilidosos e menos fortes, quanto às meninas à prática, por serem situações pedagógicas que respeitam as diferenças e promovem o desenvolvimento sem preconceitos. Pensar em aulas e grupos específicos para mulheres e com mulheres ensinando é uma boa alternativa para o incremento da participação feminina no esporte. Pereira (2015) mostra na modalidade de skate a importância da mulher como instrutora de skate, o que abre espaço para que outras mulheres ocupem seu espaço em modalidades de aventura e este pode ser um caminho para diminuir o preconceito no parkour.

\section{PARKOUR RUMO ÀS OLIMPÍADAS?}

Chagas, Rojo e Girardi (2015) entendem que as forças sociais, econômicas e midiáticas interferem diretamente na forma como o parkour se configura na atualidade. Se na sua origem foi criado como uma prática não competitiva e de transmissão gratuita, hoje ele vai se impregnando de sentido competitivo, natural em outras atividades esportivas e rende-se ao capitalismo, quando são criadas aulas em academias e atividades remuneradas aos instrutores, fatores condenados em sua criação inicial.

Além disso, a competição tem forte vínculo com as categorias capital e consumo e de forma resistente o parkour pretendia se opor a essa estruturação social.

A resistência que os traceurs buscam desenvolver não está canalizada para um único aspecto da vivência - tal como o consumo -, mas existe certo consenso em acreditar que a prática do parkour é capaz de despertar uma atitude de consciência e rejeição com relação a padrões de comportamento socialmente valorizados (SILVA; COSTA; CARVALHO, 2011, p. 133).

A Federação Internacional de Ginástica (FIG) criou para os anos de 2018 e 2019 uma série de eventos competitivos tendo o parkour como modalidade incorporada à sua organização. Nota-se que o termo parkour está colocado logo após a sigla da entidade "FIG Parkour World Cup", ou seja, a intenção final é que a modalidade se estabeleça com competições em todo o mundo e possa chegar às Olimpíadas no futuro, sendo a federação de ginástica sua "madrinha mundial" (FIG, 2017). Observa-se que como outras modalidades de aventura, skate, escalada, mountain bike e surfe, o parkour também agrega um sangue novo ao espírito olímpico, que procura revitalizar-se de tempos em tempos, para acompanhar os acontecimentos sociais. 
Verificou-se nesta pesquisa que $21,4 \%$ dos sujeitos já participaram de campeonatos e eventos competitivos de parkour, demonstrando a princípio, que a maioria dos praticantes não teve interesse ou oportunidade. Quando inquiridos sobre o desejo de participar de evento competitivo, 67,8\% têm vontade de competir, e destes, apenas 1 sujeito, que representa 1,2\% do total já participou e não pretende competir novamente na modalidade.

É possível pensar que, como o parkour nasceu como uma atividade avessa ao contexto da comparação entre os praticantes, então, são poucos eventos com essa proposta, sendo assim nem todos tiveram a oportunidade de competir, mas os dados mostram uma tendência de mudança. Há, no entanto, um fator inconclusivo, que é a aceitação das competições ou não pelos praticantes. Se de um lado a competição dá mais visibilidade midiática ao esporte, por outro, é possível que se percam os valores que originaram o parkour e sobre isso há uma comunidade resistente. Santandreu e Novo (2019) discutem essa questão revelando que a FIG tem cooptado alguns dos criadores desta modalidade para legitimar as competições dentro de sua organização esportiva, mas com uma repercussão negativa, nas redes sociais, entre os diversos grupos que praticam o parkour no mundo, ela não conseguiu organizar uma competição com representatividade e apoio, não tendo nenhuma divulgação sobre seu torneio "FIG Parkour World Cup" e nem os resultados do mesmo divulgados para que o público se interessasse pela competição.

Todavia, há outro dado a analisar, entre os 66 sujeitos que não participaram de competições, $60,6 \%$ querem competir e outros $39,4 \%$ não tem este interesse, revelando um tensionamento. Interessante ressaltar, que nos municípios de menor porte (como menos de 200 mil habitantes) $75 \%$ dos traceurs e traceuses não competiram ainda mas querem fazê-lo, isto pode indicar que nas localidades mais distantes dos grandes centros urbanos, há menor proximidade com a filosofia original do parkour, nessas regiões, há um desejo de progresso e uma relação com o conceito de esporte competitivo se sobrepondo à não competição. Sobre essa questão, Costa (2007) demonstrou, no estudo com o vôlei de praia, que a institucionalização competitiva foi um caminho virtuoso para esta prática e talvez seja esse tipo de percepção que leve tantos praticantes a seguirem pelo caminho competitivo. A informalidade do parkour demonstra pouca organização dos praticantes, que seja para desenvolver a parte pedagógica, filosófica e cultural, quanto para debater os posicionamentos contrários e a favor às intenções da FIG, e das empresas, como Red Bull, ou outras que gozam de força política e econômica e que poderão ditar as regras do parkour no futuro.

Outra informação relevante é que aqueles que já participaram de eventos tem uma média de tempo de prática de 8,3 anos, contra os 6,1 anos da média geral da amostra, portanto, não são apenas os mais jovens que estão modificando o olhar não competitivo do parkour, pessoas mais experientes estão 
entre os que competiram, talvez por curiosidade ou por se descolar da ideia de uma atividade sem vitoriosos e perdedores. Pode-se refletir sobre o fato daqueles que tem mais experiência, também terem mais habilidade $\mathrm{e}$ consequentemente se julgam aptos a vencer e a receber os prêmios, muitas vezes em dinheiro, ou bolsas esportivas do governo, pois é assim que as modalidades competitivas funcionam e essas pessoas percebem que podem obter ganhos financeiros.

Quando questionados sobre ser contra ou a favor da competitividade no parkour, quase metade dos sujeitos, ou seja, 48,8\% aprovam as competições. Entretanto, há um dado relevante, quanto menor o tempo de prática da pessoa mais ela rejeita as provas competitivas $(5,4$ anos em média de tempo de prática), já aqueles que aprovam são praticantes com média de tempo de prática mais elevada $(6,7$ anos). Isso pode indicar que pessoas que estão a mais tempo no esporte entendem que as competições podem trazer mais benefícios, ou que esperam se beneficiar das competições. Por outro lado, àqueles que estão chegando ao parkour parecem procurar uma modalidade sem competição, querem melhoria da autoestima, prazer, diversão, desenvolvimento corporal e liberdade de movimentos, que são os valores básicos da modalidade e é possível que estes praticantes que encontraram no parkour uma prática não competitiva, busquem outras formas de se movimentar, caso ele se torne uma atividade exclusivamente competitiva.

Mas, há ainda, um dado que pode comprometer as avaliações precipitadas, $28,6 \%$ dos respondentes da pesquisa informam que ainda não tem opinião formada sobre o tema e eles têm média de tempo de prática ainda maior, 6,8 anos. Essa informação colhida com os sujeitos permite dizer que há espaço para convencimento tanto a favor, quanto contra a perspectiva competitiva e é justamente dos praticantes mais velhos, isto é, daqueles que podem gerar mais influência sobre os iniciantes. Superar a visão dualista é o que propõe O'Loughlin (2012) quando discorre sobre a necessidade do parkour não ser apenas uma competição, mas permitir exprimir, igualmente, seu lado artístico e criativo.

Por fim, a pesquisa procurou entender como a influência de marcas e da comunicação midiática é vista pelos traceurs e traceuses. Quando perguntados sobre a influência das empresas nas competições de parkour, 82,1\% dos sujeitos entendem que é positivo que empresas e marcas patrocinem os eventos, provavelmente, porque percebem que em outras modalidades competitivas o patrocínio é o que sustenta o esporte e que o parkour teria a ganhar mais adeptos e visibilidade com o dinheiro dessas instituições, para eles o parkour também é um fenômeno social que segue as normas do capital, mesmo que seu ideal primário tenha se mostrado contra essa proposta. Dias, Melo e Alves Junior (2007) já alertam para o fato de que é ingênuo pensar no conceito de esporte com a separação simplista entre a competição e a cooperação, ou a seriedade e a diversão, portanto, nas práticas de aventura, em que se inclui o parkour, os 
dados obtidos nesta pesquisa estão mostrando que as pessoas incorporam os valores econômicos aos sociais, sem querer distanciá-los romanticamente.

Sobre a influência da mídia, 76,1\% responderam que consideram positiva para o parkour a divulgação da modalidade. Novamente se percebe que os praticantes não entendem como dissociar a comunicação de massa dos eventos da propagação do parkour, mesmo com a maioria sabendo que o parkour primeiro se difundiu através de sites e do contato dos praticantes nas redes sociais. Há uma ambiguidade entre comercializar o parkour como produto através da mass media, como pretende a FIG e o COI, pois isso pode levar a modalidade mais rapidamente a milhões de pessoas no mundo todo e a rejeição de muitos praticantes nas redes sociais (Facebook, WhatsApp, Instagram e Twiter) quando se trata de torná-lo competitivo e sob a égide do espírito olímpico já impregnado de corrupção, especialização precoce e doping comum às modalidades olímpicas (SANTANDREU; NOVO, 2019).

Ocorre que a contradição entre o espírito de cooperação e livre de disputas entre os praticantes, de um lado, e a força do capitalismo que se alia aos meios de comunicação para gerar a sociedade de consumo, do outro, se enfrentam no seio do parkour, gerando conflitos internos nos participantes da modalidade e pelo visto não há consensos nessa área. Segundo Pereira, Honorato e Auricchio (2020, p. 149), o parkour "[...] parece render-se à força do espetáculo, do entretenimento, da rivalidade, deixando de lado alguns de seus ideais que o fizeram surgir".

Há alguns sujeitos que apesar da pequena proporção expressam outras contradições, $13 \%$ são contra as competições, porém a favor dos patrocinadores e da cobertura e divulgação pela mídia dos eventos de parkour. Ao mesmo tempo em que se quer conservar a filosofia não competitiva, aceita-se o vínculo com o dinheiro e a comunicação profissional para que isso aconteça. Outros $6 \%$ são a favor das competições, porém, não veem como positiva a influência da mídia nas competições, revelando o desejo pela superioridade de uns sobre os outros, mas com desconfiança no trabalho da mídia, por acreditar que ela pode comunicar de forma incorreta os valores do parkour.

Na celeuma da competição no parkour, os dados mostram que 4 dos 18 sujeitos que já participaram de provas competitivas não tem um posicionamento nem a favor nem contra e se o parkour ajuda a formar um cidadão crítico, isso não se apresenta nas respostas destes sujeitos. Dos demais 12 querem continuar competindo e concordam com o apoio da mídia, o que parece mais lógico, mesmo que se leve em conta que a filosofia do esporte está sendo colocada de lado. E entre os 2 sujeitos restantes, uma pessoa que já competiu se posiciona contra as competições e afirma não ter intenção de competir novamente, porém, o outro sujeito revela seu desejo de competir, mas é contra as competições, este parece ser o caso de alguém que quer parecer correto em relação à filosofia do 
parkour, mas não renuncia aos benefícios e possibilidades de destaque social que as competições podem trazer para ele mesmo. Essas informações conflitantes dos participantes da pesquisa revelam aquilo que Aggerholm e Larsen (2017) descrevem como um aspecto mais geral e existencial do parkour, ou seja, as manobras e acrobacias que os traceurs e traceuses realizam buscando seu refinamento e perfeição não se restringem ao sentimento de fluxo que os movimentos podem trazer ao praticante, mas dialogam com as diversas versões das práticas corporais, sejam elas competições, mercantilizações, ou a própria modernidade.

Quando se trata da opinião das traceuses em relação às competições e a mídia descobriu-se que apenas uma entre as oito é contra os campeonatos, os patrocínios e a influência da mídia no parkour. Interessante relatar que ela é a mais velhas das participantes, o que indica que seja uma pessoa que mantém a filosofia original da modalidade, mas quando se olha os dados gerais da pesquisa, percebe-se que a média de tempo de prática daqueles que consideram negativa a influência da mídia e as competições do parkour é de pessoas iniciantes, ao contrário do que se vê, quando se destaca as mulheres do grupo. Essa contradição, pode ser explicada pelo fato dos homens mais experientes projetarem maiores benefícios pessoais com a entrada de dinheiro e de visibilidade nas provas competitivas, revelando mais uma vez o papel secundário da mulher nesta modalidade.

\section{CONSIDERAÇÕES FINAIS}

Silva, Costa e Carvalho (2011, p. 122) escreveram: "a maioria dos praticantes acredita permanecer fiel aos valores que originaram o movimento". Os anos se passaram e já não é possível manter essa posição frente aos dados revelados por esta pesquisa. O parkour como todos os fenômenos naturais e culturais se estabelece em constante movimento e sofrendo diversas influências dos elementos que o constituem e daqueles que estão ao seu redor, como diria Heráclito de Éfeso: "Nada é permanente, exceto a mudança". Conservar e transformar são necessidades sociais e os praticantes deverão saber lidar com elas para que o parkour sobreviva.

O perfil daqueles que optam pelo parkour trouxe algumas confirmações, que podem ajudar a entender melhor os praticantes para que se decida como prosseguir: A modalidade predomina nos grandes centros urbanos, mas vai se esparramando por todo o país, provavelmente, pelo efeito da tecnologia que permite promover o parkour independente das mídias comerciais; Os praticantes são jovens e agregam-se em grupos que misturam novatos com experientes havendo intercâmbio cultural que favorece sua continuidade; As mulheres são minoria, tal qual ocorre em muitas modalidades esportivas, principalmente aquelas em que risco, perigo e força são exigências intrínsecas e elas precisarão 
se auto produzir para que outras sigam o caminho das pioneiras, pois o preconceito masculino, não parece querem ceder espaço as traceuses.

Já sobre a questão principal da pesquisa, a competição no parkour, acredita-se que o diálogo entre os pares, mais do que nunca, deve ser aceso para que uma reflexão consciente possa nascer no seio dos grupos de parkour, sobre isso, Chagas, Rojo e Girardi, (2015, p. 31), afirmam:

O processo de espetacularização pela mídia tanto convencional, como no ciberespaço acerca do parkour, somado a existência de competições no Brasil e no mundo, são fatores que contribuem para 0 desenvolvimento de características do esporte contemporâneo na modalidade. Mesmo havendo resistências em relação à temas conceituais de praticantes, esta se mostra quase superada pelos praticantes, sendo pela incorporação de acrobacias e comercialização do ensino da prática. Neste sentido, há grandes possibilidades de uma aceitação coletiva acerca das competições relacionadas ao parkour, e a partir disto da esportivização como um todo, mesmo que à longo prazo reconhecendo as tensões entre os campos, e ressaltando a sobreposição de leis universais do campo econômico sobre o campo da prática do parkour.

Conclui-se que há intenção clara da FIG em trazer o parkour para si e há alguns grupos que a apoiam, além de empresas interessadas em oferecer seus produtos, no entanto, existem posições contra a competição na modalidade e a forma como estão sendo feitas as tratativas para esses campeonatos.

Os sujeitos desta pesquisa se posicionam de modo contraditório sobre o tema, porém, os dados mostram que a maioria quer competir, talvez, porque alguns vejam ganhos pessoais nas competições, mesmo quebrando tradições. Parece que o olhar de uma pureza de valores no parkour, não pode negar a força da modernidade sobre os desejos dos praticantes, que precisam se organizar e discutir suas questões de base em eventos próprios, para que possam definitivamente se posicionar, quer seja contra ou a favor o tema. É necessário observar que outras práticas de aventura incorporaram as competições, como é o caso do surfe, skate, escalada, entre outras gerando reconfigurações internas.

O parkour parece ter chegado mesmo ao seu ponto crítico, aquele no qual o traceur e a traceuse estão parados na beira de um edifício precisando decidir se saltam o vão deste difícil obstáculo. Aquele momento em que os riscos devem ser calculados, mas que não trazem uma fórmula matemática para isso e sim uma relação com o outro e consigo que permita reconhecer-se como ator protagonista da cena e que sua decisão será definitiva para além do bem ou do mal. Não parece ser possível simplificar o parkour numa definição única, nem com uma característica simples, talvez seja necessário compreendê-lo em sua complexidade.

\section{NotAS}




\section{CONFLITOS DE INTERESSE}

Os autores não têm conflitos de interesse, incluindo interesses financeiros específicos e relacionamentos e afiliações relevantes ao tema ou materiais discutidos no manuscrito.

\section{Autoria e COAUTORIA}

A autoria é responsável pelos conteúdos do texto. Os autores declaram que participaram de forma significativa na construção e formação desde estudo, tendo, enquanto autor, responsabilidade pública pelo conteúdo deste, pois, contribuíram diretamente para o conteúdo intelectual deste trabalho e satisfazem as exigências de autoria.

Dimitri Wuo Pereira - Concepção e desenvolvimento (desde a ideia para a investigação ou artigo, criou a hipótese); Desenho metodológico (planejamento dos métodos para gerar os resultados); Supervisão (responsável pela organização e execução do projeto e da escrita do manuscrito); Coleta e tratamento dos dados (responsável pelos experimentos, pacientes, organização dos dados); Análise / interpretação (responsável pela análise estatística, avaliação e apresentação dos resultados); Redação (responsável por escrever uma parte substantiva do manuscrito); Revisão crítica (responsável pela revisão do conteúdo intelectual do manuscrito antes da apresentação final).

Rafael Batista Mattos - Concepção e desenvolvimento (desde a ideia para a investigação ou artigo, criou a hipótese); Coleta e tratamento dos dados (responsável pelos experimentos, pacientes, organização dos dados); Análise / interpretação (responsável pela análise estatística, avaliação e apresentação dos resultados); Levantamento da literatura (participou da pesquisa bibliográfica e levantamento de artigos); Redação (responsável por escrever uma parte substantiva do manuscrito).

\section{REFERÊNCIAS}

ALVES, Carla da Silva Reis; CORSINO, Luciano Nascimento. O parkour como possibilidade para a Educação Física escolar. Motrivivência, Florianópolis, v. 25, n. 41, p. 247-257, dez. 2013.

AGGERHOLM, Kenneth; LARSEN, Signen Hojbjerre. Parkour as acrobatics: an existential phenomenological study of movement in parkour. Qualitative Research in Sport, Exercise and Health, v. 9, n. 1, p. 69-86, 2017.

BARROS, Daniel Ferreira de. Deportes de riesgo: historia del Parkour y las características de sus participantes. Lecturas EFDeportes, Buenos Aires, v. 20, n. 212, jan. 2016.

Disponível em: http://www.efdeportes.com/efd212/deportes-de-riesgo-historia-delparkour.htm. Acesso em: 20 dez. 2019.

CAILLOIS, Roger. Os jogos e os homens: a máscara e a vertigem. Trad. José Garcez Palha. Lisboa: Cotovia, 1990.

CARVALHO, Rui Gonçalves; PEREIRA, Ana Luísa. Percursos alternativos - o Parkour 
enquanto fenómeno sub(cultural). Revista Portuguesa de Ciências do Desporto. v. 8, n. 3. p. $427-440,2008$.

CARVALHO, Wallace Brehmer Gomes Rodrigues; VIANA, João Batista dos Reis. A avaliação do desenvolvimento da aptidão física através da prática do parkour no âmbito da educação física escolar. Revista Acta Brasileira do Movimento Humano, v. 6, n. 2, p. 20-33, abr./jun. 2016.

CHAGAS, Raíssa Ramos; ROJO, Jeferson Roberto; GIRARDI, Vania Lucia. O processo de esportivização de uma modalidade: o parkour enquanto prática espetacularizada. The Journal of the Latin American Socio-Cultural Studies of Sports. Curitiba, v. 5, n. 1, p. 21$33,2015$.

COSTA, Marília Maciel. Esporte de alto rendimento: produção social da modernidade, o caso do vôlei de praia. Sociedade e Estado, Brasília, v. 22, n. 1, p. 35-69, jan./abr. 2007.

DIAS, Cleber Augusto Gonçalves; MELO, Vitor Andrade de; ALVEZ JUNIOR, Edmundo. Os estudos dos esportes na natureza: desafios teóricos e conceituais. Revista Portuguesa de Ciências do Desporto, v. 7, n. 3, p. 358-367, 2007.

FERNANDES, Alessandra Vieira. Transpondo muros socioculturais: relações de gênero e empoderamento de mulheres no parkour. 254f. Dissertação (Mestrado em Educação Física) - Centro de Ciências da Saúde. Universidade Estadual de Maringá, 2018.

FERNANDES, Alessandra Vieira; GALVÃO, Lilian Kelly de Souza. Parkour e valores morais: Ser forte pra ser útil. Motrivivência, Florianópolis, v. 28, n. 47, p. 226-240, maio 2016.

FIG - Fédération Internacionale de Gymnastique. Rules for the FIG Parkour World Cup. Series 2018-2019 in cooperation with the World Action Sports Festival (WASF), v. 2, dez. 2017. Disponível em: https://www.gymnastik.se/globalassets/svenskagymnastikforbundet-tavlingsgymnastik/dokument/parkour-och-tricking/201712_pkwcup-rules-2018-19 v0.2 e.pdf. Acesso em: 27 dez. 2019.

GROSPRÊTRE, Sidney; LEPERS, Romuald. Performance characteristics of Parkour practitioners: Who are the traceurs. European Journal of Sport Sciences, v. 16, n. 6, p. 526-535, 2016.

LEITE, Neiva; AGUIAR JUNIOR, Rossine Pinto de; CIESLAK, Fabrício; ISHIYAMA, Mary; MILANO, Gerusa Eisfeld; STEFANELLO, Joice Mara Facco. Perfil de aptidão física dos praticantes de le parkour. Revista Brasileira de Medicina do Esporte, v. 17, n. 3, p. 198201, mai./jun. 2011.

MANSO, Lina. Pai do parkour estevem em Portugal, 2007. Disponível em: http://www. mundouniversitario.pt/artigos.php?art=670. Acesso em: 20 dez. 2019.

O'LOUGHLIN, Alister. A door for creativity - art and competition in parkour. Theatre, Dance and Performance Training, v. 3, n. 2, p. 192-198, 2012.

ORLANDI, Eni Puccinelli. Parkour: corpo e espaço reescrevem o sujeito. Línguas e Instrumentos Linguísticos. n. 34, p. 75-87, jul./dez. 2014.

PALAVRO, Bruna. Perfil de praticantes de parkour no Brasil. In: Congresso de Pesquisa e Extensão da FSG, 4. Anais... Faculdade da Serra Gaúcha. Caxias do Sul-RS. 04 a 06 de outubro de 2015. Disponível em: http://ojs.fsg.br/index.php/pesquisaextensao/article/view/2096 Acesso em: 27 dez. 2019. 
PEREIRA, Dimitri Wuo; PAULA, Renan Oliveira de; SILVA, André Batista; GALINDO, Camila Bianca; SANTOS, Vinicius Sampaio Feitoza dos. Esportes radicais no meio ambiente urbano no município de São Paulo. Caderno de Educação Física e Esporte, v. 15, n. $1,2017$.

PEREIRA, Dimitri Wuo; HONORATO, Tony; AURICCHIO, José Ricardo. Parkour, do início filosófico ao fim competitivo. Licere. Belo Horizonte, v. 23, n. 1, p. 134-152, mar. 2020.

PEREIRA, Cibele Garcia. Skate: Tutorial pedagógico de skate para profissionais de educação física. In: PEREIRA, Dimitri Wuo (org.). Novas experiências na aventura. São Paulo: Lexia, 2015.

SANTANDREU, Felipe; NOVO, Gabriel de Andrade. Esportivização do parkour: o projeto de uma nova modalidade da Federação Internacional de Ginástica. Deporte y sociedad, Montevideo, p. 71-94, 2019.

SEVERINO. Antonio Joaquim. Metodologia do trabalho científico. 23 ed. São Paulo: Cortez, 2007.

SILVA, Tatiana Maria Bernardo da; COSTA, Alessandra Mello da; CARVALHO, José Luis Felicio. Resistência ao Consumo em um Circuito Urbano de Parkour. Comunicação, Mídia e Consumo. São Paulo, v. 8, n. 22, p. 119-146, jul. 2011.

SILVA, Valéria. Coletivos Juvenis e Parkour no Brasil: percursos interculturais e Identidades. Tomo, n. 21, p. 63-99, 2012.

SILVA, Tatiana Maria Bernardo; COSTA, Alessandra Mello; CARVALHO, José Luis Felicio. Resistência ao consumo em um circuito urbano de parkour. Comunicação, mídia e consumo, São Paulo, v. 8, n. 22, p. 119-146, jul. 2011.

STRAMANDINOLI, Ana Luiza Martins; REMONTE, Jarbas Gomes; MARCHETTI, Paulo Henrique. Parkour: História e conceitos da modalidade. Revista Mackenzie de Educação Física e Esporte, São Paulo, v. 11, n. 2, p. 13-25, 2012.

TRALCI FILHO, Marcio Antônio; RUBIO, Katia. As identidades da atleta brasileira: os "pontos de apego temporários" da mulher na vida esportiva. Movimento, Porto Alegre, v. 18 , n. 2, p. 255-275, abr./jun. 2012.

UVINHA, Ricardo Ricci. Juventude Lazer e Esportes Radicais. São Paulo: Manole, 2001.

WHEATON, Billie; O'LOUGHLIN, Alister. Informal sport, institutionalization, and sport policy: challenging the sportization of parkour in England. International Journal of sport Policy and Politics, v. 9, n. 1, p. 71-88, 2017. 
A revista Conexões utiliza a Licença Internacional Creative Commons Atribuição 4.0, preservando assim, a integridade dos artigos em ambiente de acesso aberto.

A Revista Conexões é integrante do Portal de Periódicos Eletrônicos da Unicamp e associado/membro das seguintes instituições:

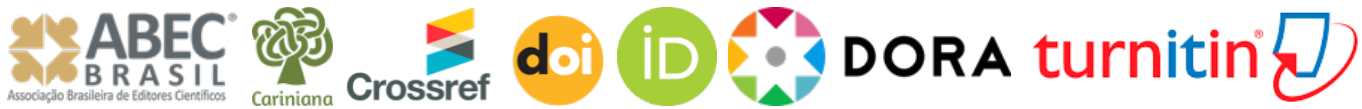

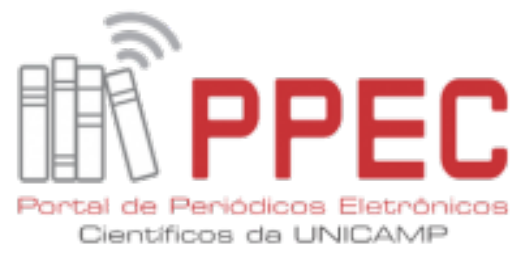

